\title{
Oral Hygiene:
}

\section{Knowledge, Attitude and Practice among School Children, Lahore}

\author{
Chanda Jabeen, Gulshan Umbreen
}

\section{ABSTRACT}

BACKGROUND: Assessment of the oral health is very important to organize the community based programs which is a key of promoting the health system and this includes assessment of knowledge, attitude and practice of oral hygiene. Different results of Researches have proved that Oral health practices are poor in Pakistan. Specially, majority of population are school going children, who is suffering from dental caries and periodontal diseases. So according to need of health development in Pakistan, Oral hygiene KAP Assessment is a basic step for policy evolution.

AIM: To assess the Oral hygiene knowledge, attitude and practice among school children aged 12-14 years, students of class 6 to 7 group at Ali Raza Abad, Lahore.

METHOD: A cross sectional community based survey was conducted at Ali Raza Abad, Lahore. Convenience sampling technique was used to collect the data from respondents. Study conducted in November-December 2015. Closed ended questionnaire was used. Data was gathered from school children aged 12-14 years, students of class 6 to 7 group living at community Ali Raza Abad Lahore. SPSS version 20 was used to analyze the data and descriptive statistics and chi- square was applied. Statistical difference present if $p$ value is less than 0.05 .

RESULTS: Out of total children, $64 \%$ children did not have knowledge about fluoride, statistical difference found between both genders with $p$ value 0.007 which shows female students are more knowledgeable. $50 \%$ of children do not visit the dentists, $26 \%$ visited during pain. $67 \%$ said that regular visit to the dentists is necessary. Reason behind not visiting the dentists are high cost treatment $14 \%$, no clinic nearby $\mathbf{2 8} \%$, no time $\mathbf{5 8 \%}$. $\mathbf{9 8 \%}$ children brush their teeth daily. It was seen that $54 \%$ subjects brush their teeth once a day. No statistical difference found between both genders related to oral hygiene attitude and practices.

CONCLUSION: It is concluded that students have adequate knowledge about dental hygiene but they do not know the use of fluoride and its function. Female students are more knowledgeable as compared to the male students. Practices are not fair enough has mostly brushed less than two minutes. There is a great need of providing dental services in the schools located in the rural areas because majority did not visit the doctors due to time shortage.

KEY WORDS: Oral hygiene, Knowledge, Attitude, Practice and School children

This article may be cited as: Jabeen C, Umbreen G. Oral Hygiene: Knowledge, Attitude and Practice among School Children, Lahore. J Liaquat Uni Med Health Sci. 2017;16(03):176-80. doi: 10.22442/jlumhs.171630529

\section{INTRODUCTION}

Oral hygiene is the method of keeping oral cavity free from pathological conditions that affect mouth like gum diseases, cavities, mouth sores and ulcers ${ }^{1}$. As oral health affect overall health of an child, it is therefore of paramount importance to maintain oral hygiene of school going children. If community-oriented oral health promotion programs are to be successful, the knowledge of the latest status of oral health of community is of vital importance ${ }^{2}$. Oral health can best be assessed by knowing knowledge attitude and practices of oral hygiene.

At school children's academic performance is affected due to dental caries, consequently more than 50 million school hours are lost per year ${ }^{3}$. Recent studies indicate there is a two way relationship between general health and oral health. Systematic diseases affect oral health similarly chronic oral inflammatory diseases; dental cavities and periodontal (gum) disease have bad effects on general health. Inappropriate oral health also contributes in cardiovascular disease, respiratory infections, stroke and nutritional problems ${ }^{4}$.

Dental caries is the most prevalent dental problem in most of the population in the world. In African countries dental caries has least prevalence but in Asian and Latin American countries almost $90 \%$ adults and school going children suffering from dental 
caries ${ }^{5}$. The published literature showed that Pakistan is among countries where oral health is considered bad and majority of school going children s has dental caries and periodontal diseases ${ }^{6}$. In Pakistan, it has been estimated that dental caries (tooth decay) is the single most common chronic childhood disease; 5 times more widespread than asthma and 7 times more common than hay fever. Therefore, assessment of oral health using knowledge, attitude and practices (KAP) survey may be considered as a fundamental step for the policy development focused to improve oral health in Pakistan ${ }^{7}$.

\section{OBJECTIVES}

To assess the Oral hygiene knowledge, attitude and practice among school children aged 12-14 years in Ali Raza Abad, Lahore.

To assess the difference in Oral hygiene knowledge, attitude and practice in relation to gender.

\section{MATERIAL AND METHOD}

Research Design: The design of this study was Descriptive cross sectional. Convenience sampling technique was used for this study. Study conducted in November- December 2015.

Targeted Population: The study was conducted at Government School Ali Raza Abad. School going children of Ali Raza Abad was the targeted population.

Setting: Ali Raza Abad Lahore.

Inclusion Criteria: School going children ages of 12 to 14 years. Both male and female students were included. They were young enough to know and complete the questionnaire.

Exclusion Criteria: Physically and mentally disabled children and those who not meet the inclusion criteria were excluded from study.

Sample Size: To calculate sample size from a population Slovin's formula is used ${ }^{8}$

So, sample size was determined by using Slovin's formula which is $\mathrm{n}=\frac{\mathrm{N}}{1+(\mathrm{N})(\mathrm{e}) 2}$

Desired sample size $=\mathrm{n}=$ ?

Population $=\mathrm{N}=1000$

Margin of error $=\mathrm{e}=0.1 \%$ (If we take confidence interval 90\%)

$\mathrm{n}=\frac{1000}{1+(900)(0.1) 2}=\frac{1000}{1+9}=\frac{1000}{10}=100$

Our desired sample size is hundred in this study.

Ethical Consideration: A written application mentioning the purpose of the project with attached questionnaire was submitted to the school's principals and written permission was taken. Individual consents also taken from each student.

Research Tool: A knowledge, attitude and practice survey questionnaire was filled by the students. Self-modified questionnaire were made according to the target population.

Data Gathering Plan: All questionnaires were completed and data collected in the classrooms. We were available to clarify their doubts about any point during the course of completing the questionnaire.

Data Analyzes: The data was analyzed by using Statistical Package for Social Sciences (SPSS) version 20 and descriptive statistics and chi square applied.

\section{RESULTS}

A total of one hundred student children of which, 54 females and 46 males in the age group 12 to 14 years were included in this study. Data regarding Knowledge, attitude and practice about oral hygiene was collected.

\section{Knowledge and awareness of dental and general health}

Out of total 100 , Only 60 children said that carious/ decayed teeth affect teeth appearance while 24 students $1.56 \pm 0.76$ said that carious/decayed teeth do not affect teeth appearance however 16 children did not have knowledge about it. Statistical significant difference found between both genders with $p$ value 0.004 as female students have more knowledge than male students that carious/decayed teeth affect teeth appearance. Ninety eight children have right knowledge that sweets and fizzy drinks affect the dental health while 2 students $1.02 \pm 0.141$ said that sweets and fizzy drinks do not affect the dental, no statistical significant difference found between both genders. Ninety one children knew that brushing the teeth prevent dental decay however 5 students 1.14 \pm 0.472 did not know, no statistical significant difference found between both genders. It was surprising that 64 children did not have knowledge about fluoride, 31children $2.33 \pm 0.922$ knew that fluoride strengthen the teeth, statistical difference found between both genders with $p$ value 0.007 which shows female students are more knowledgeable regarding this question. Do the dental diseases impact the general body health? 78 students said yes, 5 students no and 15 students said do not know 1.37 \pm 0.734 and no difference found between both genders. 96 know that care about teeth is important as any part of the body, 3 students did not know about it while 1 student $1.07 \pm 0.355$ had wrong knowledge that care about teeth is not important as any part of the body, no difference found between both genders. 


\section{TABLE I: KNOWLEDGE AND AWARENESS OF} DENTAL AND GENERAL HEALTH

\begin{tabular}{|c|c|}
\hline Questions & Percentage \\
\hline $\begin{array}{l}\text { - Carious/Decayed teeth affect teeth } \\
\text { Yes } \\
\text { No } \\
\text { Don't Know } \\
\text { - Sweets and fizzy drinks affect the dental } \\
\text { Yes } \\
\text { No } \\
\text { Don't Know } \\
\text { Yes Brushing the teeth prevent dental decay. } \\
\text { No } \\
\text { Don't Know } \\
\text { Yes Fluoride strengthens the teeth. } \\
\text { No } \\
\text { Don't Know } \\
\text { - Do the dental diseases impact the general } \\
\text { Yes body health? } \\
\text { No } \\
\text { Don't Know } \\
\text { - Care about teeth is important as any part of } \\
\text { Yes the body? } \\
\text { No } \\
\text { Don't Know }\end{array}$ & $\begin{array}{c}60 \\
24 \\
16 \\
\\
98 \\
2 \\
0 \\
\\
91 \\
4 \\
5 \\
\\
31 \\
5 \\
64\end{array}$ \\
\hline
\end{tabular}

\section{Attitudes toward professional dental care}

Fifty children do not visit the dentists, 26 children visited during pain. Sixty seven children said that regular visit to the dentists is necessary, 15 children said it is not necessary while 18 children $1.51 \pm 0.785$ did not know about it, statistical difference found between both genders as more females has positive attitude as compared to male students. Reason behind not visiting the dentists are high cost treatment according to 14 children, no clinic nearby said by 28 children, no time said by 58 children $0.44 \pm 0.729$, no difference found between both genders. Mostly students showed positive attitude toward dentist. 72 children said that dentist cares properly about the patient, 25children did not know and only 3children $1.53 \pm 0.870$ said that dentists do not care properly about the patient, no statistical difference found between both genders.

TABLE II: ATTITUDES TOWARD PROFESSIONAL DENTAL CARE

\begin{tabular}{|l|c|}
\hline \multicolumn{1}{|c|}{ Questions } & Percentage \\
\hline - How often do you visit the dentist? & \\
During dental pain & 26 \\
Occasionally & 24 \\
Never visited & 50 \\
\hline
\end{tabular}

\begin{tabular}{|l|c|}
\hline$\quad$ Are regular visit to dentist necessary? & \\
Yes & 67 \\
No & 15 \\
Don't Know & 18 \\
- Reason behind not visiting the dentist. & 14 \\
High cost treatment & 28 \\
No clinic nearby & 58 \\
No time & 72 \\
$-\quad$ Dentist cares properly about the patient? & 3 \\
Yes & 25 \\
No & \\
Don't Know & \\
\hline
\end{tabular}

Oral Hygiene Practice: The oral hygiene practices of our study sample indicate that out of 100,98 children brush their teeth while 2 children $1.02 \pm 0.141$ do not brush their teeth. No statistically significant difference found in relation to gender as $p$ value is greater than 0.44 . It was seen that 54 subjects brush their teeth once a day while 43 brush twice a day only 3 children $2.40 \pm 0.55$ do brushing less than once per day with no statistical difference between both genders. All children used toothbrush and paste to clean their teeth. None of them used mouthwash or any other thing with all 100 children $01 \pm 0.0$ used tooth paste and brush. 96 children brush their teeth in morning, only 3 children $1.07 \pm 0.355$ brushed at night. Only 66 children brush their teeth for two minutes while 31children used to brush for one minutes and 3children less than one minute $0.63 \pm 0.544$, no statistically significance difference found between two genders related to oral hygiene practice.

\section{TABLE III: ORAL HYGIENE PRACTICE}

\begin{tabular}{|l|c|}
\hline \multicolumn{1}{|c|}{ Questions } & Percentage \\
\hline - Do you brush your teeth? & 98 \\
Yes & 2 \\
NO How often do you brush your teeth? & \\
Less than once per day & 3 \\
Once per day & 54 \\
Twice a day & 43 \\
Bush toothpaste & 100 \\
Brush for cleaning your teeth? & 0 \\
Mouth wash & 0 \\
Any other & 96 \\
- When do you brush your teeth? & 1 \\
Morning & 3 \\
Noon (after lunch) & \\
Before going to bed & 3 \\
- How long do you brush your teeth? & 31 \\
Less than one minute & 66 \\
One minute & \\
Two minutes & \\
\hline
\end{tabular}

\section{DISCUSSION}

In our study ninety six percent children brush their teeth in morning, and have knowledge that sweets are 
not good for their teeth health is similar to the study conducted in Jordanian ${ }^{9}$. Ninety one percent children knew that brushing prevent tooth decay which is opposite to the result of study conducted in Karachi where only high socio economic school children have knowledge about it moreover in our study hundred percent children used tooth brush and tooth paste all are belong to low socio economic group which is opposite the result of the study conducted in Karachi where only forty nine percent subjects used tooth brush and tooth paste ${ }^{10}$. It was surprising that $64 \%$ children did not have knowledge about fluoride, which is opposite to the study conducted in Chennai, India where almost $55 \%$ students have knowledge that fluoride strengthened teeth ${ }^{11}$. All children used toothbrush and paste to clean their teeth. None of them used mouthwash or any other thing because of low socio economic status or poor availability this finding same to the Africa where school going children belonging to poor families do not use flossing and any other thing due to poverty ${ }^{12}$. Children visited the dentist when they had pain and reasons for not visiting the dental clinics are the no availability of clinics and high cost treatment, these reasons also found in a survey conducted in USA ${ }^{13}$. In this study majority of students showed positive attitude toward dentist which is similar to the other studies conducted in Pakistan, ${ }^{70,11}$. In our study children do not visit dental clinics regularly, which is similar to the study conducted in China ${ }^{14}$.

\section{CONCLUSION}

It is concluded that students have adequate knowledge about dental hygiene but they do not know the use of fluoride and its function. Female students are more knowledgeable as compared to the male students. Students showed positive attitude toward dentist but they only visited the dental clinics when they have toothache because of no availability of dental clinics nearby and they do not have time. Practices are not fair enough as mostly brushed less than two minutes. So, there is a great need of giving education regarding the use of fluoride tooth paste. Moreover male students need more education as compared to female students living in rural areas. Dental caries occur because of not having dental clinics in rural areas. There is a great need of providing dental services in the schools located in the rural areas because majority did not visit the doctors due to time shortage.

\section{LIMITATIONS}

Limitations of this study were that we did not visit all schools present in the community. Sample size is not significant to apply the result to whole community.
Since the study was conducted on children of considerably sensible age group who are prone to make a positive impression about them, hence the results of the oral health practices could be biased.

\section{RECOMMENDATIONS}

- The study can be conducted on the large scale sample to validate and for better generalization of the findings

- Regular Dental check-up may be conducted for school children.

- School syllabus may include topic related to Dental hygiene.

- Children should be educated regarding the dental hygiene in each school of rural area.

\section{ACKNOWLEDGEMENTS}

- We would like to give thank our Parents.

- No conflict of interest is present and this project is not funded by any agencies. This is totally personally funded project by authors.

\section{REFERENCES}

1. WHO. "Health topics: Oral health". [cited 2015 December]; Available from: http://www.who.int/ topics/oral_health/en/.

2. Harikiran AG, Pallavi SK, Hariprakash $S$, Ashutosh, Nagesh KS. Oral health-related KAP among 11-to 12-year-old school children in a government-aided missionary school of Bangalore city. Indian Journal of Dental Research. 2008; 19 (3):236-42.

3. Gift HC, Reisine ST, Larach DC. The social impact of dental problems and visits. Am J Public Health. 1992; 82(12):1663-8. Erratum in: Am J Public Health. 1993; 83(6):816.

4. Bjertness $E$. The importance of oral hygiene on variation in dental caries in adults. Acta Odontol Scand. 1991; 49(2):97-102.

5. Petersen PE. The World Oral Health Report 2003: continuous improvement of oral health in the 21st century-the approach of the WHO Global Oral Health Programme. Community Dent Oral Epidemiol. 2003; 31(s1):3-23.

6. Haleem A, Khan AA. Dental caries and oral hygiene status of 12 years old school children in Pakistan. Pak J Med Res. 2001; 40(4):138-42.

7. Vakani F, Basaria N, Katpar S. Oral hygiene KAP assessment and DMFT scoring among children aged 11-12 years in an urban school of Karachi. JCPSP. 2011; 21(4):223-6.

8. Ellen S. Slovin's formula sampling techniques 2012 [cited 2015 April 7]; Available from: http:// www.ehow.com/way_5475547_slovins-formulasampling-techniques.html. 
9. Al-Omiri MK, Al-Wahadni AM, Saeed KN. Oral health attitudes, knowledge, and behavior among school children in North Jordan. J Dent Educ. 2006; 70(2):179-87.

10. Mirza BAQ, Izhar F, Syed A, Khan AA. Oral health attitudes, knowledge, and behavior amongst high and low socioeconomic school going children in Lahore, Pakistan. Pak Oral Dent J. 2011; 31 (2):396-401.

11. Priya M, Devdas K, Amarlal D, Venkatachalapathy A. Oral health attitudes, knowledge and practice among school children in Chennai, India. J Educ Ethics Dent. 2013; 3(1):26-33.
12. Varenne B, Petersen PE, Ouattara $S$. Oral health behaviour of children and adults in urban and rural areas of Burkina Faso, Africa. Int Dent J. 2006; 56 (2):61-70.

13. Liu J, Probst JC, Martin AB, Wang JY, Salinas CF. Disparities in dental insurance coverage and dental care among US children: the National Survey of Children's Health. Pediatrics. 2007; 119 (Suppl1):S12-S21.

14. Zhu L, Petersen PE, Wang HY, Bian JY, Zhang $B X$. Oral health knowledge, attitudes and behaviour of children and adolescents in China. Int Dent J. 2003; 53(5):289-98.

AUTHOR AFFILIATION:

Chanda Jabeen (Corresponding Author)

Lahore School of Nursing

The University of Lahore, Punjab-Pakistan.

E-mail: chandajabeen786@gmail.com

Gulshan Umbreen

Lahore School of Nursing

The University of Lahore, Punjab-Pakistan. 